\title{
Entrepreneurship Education Meets FabLab: Lessons Learned with Teenagers
}

\author{
Heidi Hartikainen \\ University of Oulu \\ heidi.hartikainen@oulu.fi \\ Marianne Kinnula \\ University of Oulu \\ marianne.kinnula@oulu.fi
}

\author{
Leena Ventä-Olkkonen \\ University of Oulu \\ leena.venta-olkkonen@oulu.fi \\ Netta Iivari \\ University of Oulu \\ netta.iivari@oulu.fi
}

\begin{abstract}
Digital fabrication, making and entrepreneurship education all have potential to empower children and increase their abilities to participate and shape the society and digitalization within, and act as active "protagonists" instead of passive consumers. While the potential of these educational trends has been acknowledged, they have mostly been studied separately and without specific focus on challenges involved. We have conducted a business innovation project with teenagers at school, combining elements of digital fabrication, making and entrepreneurship education. Our qualitative, data-driven analysis focused on the process and the challenges involved in the endeavor. As a result, we generate a list of lessons learned associated with teenagers adopting the role of a protagonist, driving business innovation. Our main findings relate to the lessons learned on the importance of balancing the making activities with the entrepreneurial aspects and negotiating the roles and responsibilities between the adult participants.
\end{abstract}

\section{CCS CONCEPTS}

- Human-centered computing; • Human computer interaction (HCI); • Empirical studies in HCI;

\section{KEYWORDS}

Formal education, Technology education, Innovation education, Entrepreneurship education, Schools, Teachers, Students, Teens, Children, Protagonist, Challenges

\section{ACM Reference Format:}

Heidi Hartikainen, Leena Ventä-Olkkonen, Marianne Kinnula, and Netta Iivari. 2021. Entrepreneurship Education Meets FabLab: Lessons Learned with Teenagers. In FabLearn Europe / MakeEd 2021 - An International Conference on Computing, Design and Making in Education (FabLearn Europe MakeEd 2021), June 02, 03, 2021, St. Gallen, Switzerland. ACM, New York, NY, USA, 9 pages.

Permission to make digital or hard copies of all or part of this work for personal or classroom use is granted without fee provided that copies are not made or distributed for profit or commercial advantage and that copies bear this notice and the full citation on the first page. Copyrights for components of this work owned by others than the author(s) must be honored. Abstracting with credit is permitted. To copy otherwise, or republish, to post on servers or to redistribute to lists, requires prior specific permission and/or a fee. Request permissions from permissions@acm.org.

FabLearn Europe / MakeEd 2021, June 02, 03, 2021, St. Gallen, Switzerland

(c) 2021 Copyright held by the owner/author(s). Publication rights licensed to ACM

ACM ISBN $x x x-x-x x x x-x x x x-x$

https://doi.org/10.1145/Xxxxxxx.Xxxxxxx

\section{INTRODUCTION}

In this paper, we scrutinize a project that combined entrepreneurship education with digital fabrication and making activities as a part of children's schoolwork. In the project, teenagers worked in groups towards coming up with a business idea and a business plan. In addition, they engaged in digital fabrication for example through designing a logo for their business and prototyping products. European Commission's European Reference Framework on Key Competencies for Lifelong Learning states that one of the key skills, the "sense of initiative and entrepreneurship", should be acquired through education [7]. Entrepreneurship education highlights trying, learning by doing, teamwork, and project work. It develops individual competencies, but also trains young people to contribute towards economic development and sustainable future communities. Overall, entrepreneurship education teaches skills and the attitude towards success in studies, future work and life in general. (see $[19,37])$. It is no wonder entrepreneurship education is already one of the mainstream parts of contemporary school curricula.

Engaging children in digital fabrication, design and making has also been acknowledged to facilitate children's learning in multiple ways and to have the potential to teach children a number of $21^{\text {st }}$ century skills $[2,9,13,29,38]$, i.e. skills that are needed for growth, employment and participation in today's society $[5,33]$. Thus, combining digital fabrication and making with the education of children is a contemporary trend, and it has aroused interest among practitioners at schools as well as researchers within disciplines such as educational sciences, Human-Computer Interaction (HCI) and Child-Computer Interaction (CCI). According to the maker movement and maker mindset, anyone can make almost anything. While democratizing innovation is the traditional focus of maker movement, there is also an entrepreneurial vision that positions making as an enabler of business innovation and a key to entrepreneurship $[22,38]$. However, studies that combine entrepreneurship education with digital fabrication and making are scarce [35, 36], even if both entrepreneurship education and digital fabrication and making have been widely studied separately. Studies on digital fabrication and making tend also to focus on success stories rather than on scrutinizing the challenges involved [25]. We aim to fill these gaps, asking as our research question, What are the challenges involved in combining digital fabrication with entrepreneurship education in the school context? We claim that combining digital fabrication and making with entrepreneurship education enables bringing in new, valuable aspects for the role of 'the Design Protagonist' for 
children [18]: this role positions children as drivers of digital technology development and emphasizes their critical reflection on digital technologies in their everyday lives and in the society. We argue understanding about business and innovation aspects is a valuable element to be included in the Protagonist role. Contribution of this paper is a detailed description of the process and an in-depth analysis of experiences gained, outlining a number of challenges encountered and associated lessons learned. We believe they will be of use to the diverse group of researchers and practitioners coming together in Fab Labs and makerspaces, in and out of school environment, to work with children with an interest to encourage children to adopt the Protagonist role. Prior literature has shown the practitioners form a very diverse group concerning their experience and expertise, some lacking experience in pedagogy, others having very limited background in technology and making [23-25, 28]. Hence, we expect discussion about potential challenges and associated lessons learned to be valuable.

This paper is structured as follows. Next, we discuss related research on digital fabrication, making and entrepreneurship education with children. This is followed by a description of methods and materials in this study. Then, we present findings related to integrating digital fabrication, making and entrepreneurship education with children in the context of school. Finally, we discuss the findings and conclude our work.

\section{RELATED RESEARCH}

There is extensive discussion on the benefits of maker movement for the education of children: making in education, making-based education, and integration of digital fabrication and making activities into education have raised researchers' interest in a number of disciplines, most notably within educational sciences, HCI and CCI. Making in education is seen to advocate and implement practice-based learning, constructionist learning, experimental learning, participatory learning, self-driven learning, learning by doing, project-based learning, problem-based learning - all seen as valuable for young learners (see [17]). While many studies consider the value of digital fabrication and making in terms of scaffolding learning in general, some focus more specifically on their role in children's technology comprehension and education: such education should equip children with skills and competences for the meaningful use of digital technology but also with skills for making and shaping digital technology as well as for critically reflecting on it and its trajectories in our everyday life and in the society (see [6,16,18,31]) Digital fabrication and making are seen as offering great potential in this respect, enabling children to adopt the role of the Protagonist [18].

There are several CCI/FabLearn studies addressing digital fabrication and making in the context of non-formal education of children, such as in different computing, programming, robotics, digital fabrication or making clubs or events, taking place in a variety of spaces outside of school such as in libraries, museums or FabLabs (e.g [10, 27, 34]). CCI research has also identified ways by which digital fabrication and making can be integrated with schoolwork or curriculum (e.g. $[1,6,16,18,31])$. The studies combine digital fabrication and making with different subjects: math, social studies, science, and/or arts or crafts. However, they seldom address entrepreneurship, which is surprising as there is a lot of potential in the combination of business innovation and entrepreneurship with digital fabrication and making [12].

In a sense, one could say digital fabrication and making are far apart from business and entrepreneurship. Maker movement can be argued to emphasize democratizing innovation: it is about putting digital fabrication means and tools to the hands of ordinary people, who are empowered with them to create personally meaningful objects and tools for solving of personally relevant problems. Maker movement has also early on prioritized collaboration and communal aspects: sharing, giving and participation [14]. Then again, this view represents a hobbyist vision of making that can be contrasted with an entrepreneurial one $[22,38]$, which reveals clear connections between making and entrepreneurship. Within the entrepreneurial vision, making is seen to offer a hotbed for innovation [8, 11, 32], even as a key to entrepreneurship [3, 4, 22, 30] and the maker community having potential to produce new talent for business [8].

Entrepreneurship education has been widely studied in the university context but less often with children [26]. Even though it is argued that the skills and mindset should be taught to young children already $[20,21,26]$ and that entrepreneurship education should be a part of lifelong learning and also integrated into the curricula [39]. With children, the focus of entrepreneurship education should, on the one hand, be on the development of skills that are useful for entrepreneurs, such as creativity, the spirit of enterprise, and independence, which can also be carried on to the next levels of education, and on the other hand, on introducing entrepreneurship as a potential future career [12, 26]. The combination of digital fabrication and making with entrepreneurship education has been acknowledged as having potential to produce the 'digital innovators of future' [16] and found to increase university students' entrepreneurial self-efficacy and entrepreneurial intentions [24]. Attempts to try the combination out in education have still been rarely reported $[12,15,35,36,38]$ and very little is known on how to do it in practice. Hollauf et al. [15] propose it is important to motivate children (allow mistakes, solving problems that are easily relatable, start with easy tasks), have an open process (asking open design questions, scaffolding children's work but encouraging them to do as much as possible themselves, making technology exploration as easy as possible), and open outcomes (iterative process, focus on learning from the process itself, aiming for positive outcomes). However, the existing studies do not touch much the nuances of the process yet, which we aim to do with this study.

\section{METHODS}

\subsection{Study Set Up}

The work reported in this paper was a part of a larger research project, implemented in collaboration with three local schools, children with different ages, and volunteering teachers. The general project aim was to develop frameworks for teaching digital fabrication and making for children and incorporating that into the school curricula. The researchers planned and designed the structure and content for each session and delivered materials for the teachers beforehand to look through and comment. Work with the children included design and making activities, with a different emphasis 
Table 1: Session lengths and topics

\begin{tabular}{llll}
\hline Session & Min & Topic & Location \\
\hline 1 & 75 & Ideation: brainstorming business ideas & School \\
2 & 75 & Introduction to digital fabrication: general knowledge & School \\
3 & 75 & Introduction to digital fabrication: getting to know FabLab & FabLab \\
4 & 75 & Background research: Identifying customers and competitors & University \\
5 & 75 & Acquiring basic skills in 2D and 3D design and making & School \\
6 & 75 & Acquiring basic skills in 2D and 3D design and making & FabLab \\
7 & 75 & Designing and making something related to the business idea & FabLab \\
8 & 185 & Designing and making something related to the business idea & FabLab \\
9 & 160 & Designing and making something related to the business idea, preparing for pitching & FabLab \\
10 & 160 & Pitching business ideas to investors & University \\
\hline
\end{tabular}

with different aged children. Researchers planning the process and designing the learning material included experts in digital fabrication, design and making with children, pedagogy, and innovation education and entrepreneurship.

In this paper, we report our work with 14-15-year-olds: a multidisciplinary learning module that centered around entrepreneurship education, conducted in collaboration with an English teacher and a social science teacher. The main goal for the students was to come up with a business idea and make a business plan in groups and pitch their ideas in a final seminar. In addition, a goal was for them to learn some basics of digital fabrication during this process. They learned the basics of Inkscape and Tinkercad in a structured manner with an instructor, and then designed and fabricated their own designs for stickers, keychains, and small 3D objects independently, facilitated by FabLab instructors. In addition, the students ideated, designed, and fabricated something as a part of their group work, to support their business idea. The children ideated what this 'something' could be, and researchers and instructors only facilitated the design and fabrication process.

The 10 sessions comprised approximately 17 hours in total, divided between 8 days, with the following high-level topics: 1) Ideation, 2) Background research, 3) 2D and 3D design and making, 4) Pitching the idea. Learning outcomes of the project were not graded. A typical session included a recap of the project purpose and what had been previously done, the goal of the daily session, and division of tasks to groups, presented using slides. Students were free to carry out the tasks as they saw to fit, with teachers and researchers trying to keep the students' focus on the task and helping them when needed. At the end of each session, there was a recap.

Two teachers participated in the research with 27 students, divided into groups by the teachers. The division was done to avoid all-girl and all-boy groups, and friends working together. In addition, teachers tried to ensure all groups had motivated conscientious students and avoided putting teens that do not get along together. They had also considered learning difficulties and mixed together teens with different preferred ways of learning. A goal for teachers in addition to learning about entrepreneurship was enhanced group working skills: learning to work with everyone, and to support each other's ideas.

\subsection{Research Data and Analysis}

The data used in this study includes field notes and observations from five researchers involved in the project, as well as semistructured ending interviews with two teachers, and 14 teens, who had parental consent and wanted to participate in the interview. Student interviews included questions related to their background (technology usage, digital fabrication, group work experiences, learning habits), creation of the business idea, group work during the project, perceived learning, and additional feedback on the project. Teacher interviews included questions related to expectations of the project, roles and responsibilities of different actors and the interaction between them, their views concerning integrating making activities in school and overall project feedback. Both the teacher and the student interviews were carried out at school during normal school hours. They were recorded and transcribed to allow for qualitative content analysis.

The data analysis was inductive, data-driven and proceeded the following way. The first author organized and went through the researcher field notes and observations from each session, wrote down how they unfolded, and what challenges the researchers had identified. Next, the first author went through the notes and transcripts from ending interviews of teachers and students and identified the challenges and key takeaways from each session. The findings were illustrated with the help of quotes from the teachers and four students. After the data analysis, we decided to use quotes from teens who belonged to the same group: their interviews offered unique insights into how different teens observe different situations as well as their group dynamics. Once the first draft of findings was formulated, it was shared with the rest of the research team who discussed and refined the presentation and collaborated in identifying lessons learned and formulating discussion.

\section{FINDINGS}

Next, we present our results in a chronological order as they unfolded in our project, illustrating them with the help of researcher field notes and observations, combined with the insights from the interviews. In addition, we summarize the lessons learned related to each process phase. 


\subsection{Ideation: Brainstorming Business Ideas}

We met at the school where the teacher opened Session 1 and introduced the project. Then, researchers introduced the project goals and schedule in detail. The students were given a notebook and a pen, a laser cut keychain with the research project logo, the project timetable and a business plan template. The keychain sparked interest, and many kept playing with it. We oriented students into entrepreneurship by inviting them to think 'How to make the world a better place with business'. We discussed how companies make profit selling services or products, and how they make sure they respond to customer needs - thus making the world a better place. We gave examples such as Netflix and Spotify that let users enjoy content anywhere, mobile phones that make it easier to connect with others, and renewable energy that makes the world cleaner. We did not talk about making culture or products that can be made in a FabLab as we thought it might have guided their thinking. We gave students a task to come up with one business idea individually, to discuss these ideas in groups, and to select one to work with. Groups were instructed to include in their business plan the problem or need they want to solve, the solution they offer, and customer segments.

While groups were engaged, ideation still proved challenging Some were not happy with the group division and turned to friends instead. Some worked alone without much contact with their group. Some did not grasp what they were supposed to do. One student explained she had difficulties as she did not fully grasp what the goal was: I didn't understand what we were supposed to do so I didn't do anything. [..] The start of the project was unclear (Girl 1). One student later suggested instruction in writing would be a good idea, to overcome the confusion that rises in groups concerning tasks: One person misses one thing, the other misses something else. If instructions are only given verbally, you have to go through it over and over again. If they are in writing, you can always check what you need to do. (Boy 1) Researchers and teachers circled the groups to get them focused and working together. We tried to explain that there are no bad ideas, and what the students come up with does not need to be fancy. At the end, most of the groups had a rough idea of what they wanted to do, and they shared it with the class. The atmosphere was positive, and the students joked around, perhaps noticing that others did not produce perfect ideas either and that it was fine.

After the session, we got feedback that groups would have liked more time to work on ideating - working in assigned groups was not as easy as working with friends, in addition some felt they had to pick "the least bad" because of time constraints: It was difficult because we didn't have that much time to figure our idea. [...] the start was too fast. (Boy 2) It was hard to create an idea because most of the ideas we first came up with were either illegal or too hard. [...] We had to compromise and pick an idea that was worse. (Boy 1)

Lessons learned:

- Be concrete with the students about project goals to avoid confusion.

- Use structured ideation methods and reserve ample time: Open ended tasks are challenging especially when working with assigned groups.
- Provide written instructions to accompany verbal ones to accommodate preferred ways of learning.

\subsection{Introduction to Digital Fabrication}

We wanted the students to have some practical understanding of what can be done with digital fabrication before they continue their business planning, as we know from previous research that otherwise the expectations can be unrealistic [16]. Because of this, in session 2 arranged at school premises, researchers explained to students that while digital fabrication is not the focus of the project, they will be using FabLab to design and make something related to their business idea later. We introduced the processes of 2D design and cutting, and 3D design and printing, and offered small examples of possible projects they could do such as designing a logo for the business and printing it on T-shirts, or if they have a product, a quick prototype.

In Session 3, we met at the FabLab, introduced the space and instructors, and did small projects with laser cutter and 3D printer to show them in action. Some students lingered back, seemingly bored and not paying attention. Most huddled closer, but it is likely those standing in the back could not hear clearly as the space is noisy due to machines humming. Because of the size of the group, not all got a good look at the process. In the FabLab computer space, we tasked all groups to browse Thingiverse and pick a small 3D item to print out. We did not interfere unless groups asked questions, as we wanted them to have a relaxed start to working in the FabLab. Groups were chatty and upbeat, and all found something to print. A student explained they found the space interesting: Working at the university was nice, the researchers were a lot nicer than our teachers. The environment there was modern and nice and using these new machines was interesting. (Boy 1). A teacher echoed this and noted that visiting FabLab was a welcomed change to a normal school day: Kids are just happy when they "don't have school" but they are doing something different. (Teacher 1) Students were excited to see 3D objects printed, some played with them or kept them in their hands. Some were however disappointed they did not turn out as envisioned based on what they saw in Thingiverse (i.e. they were smaller than they thought, or a colorful model was plain when printed). We used this opportunity to explain to students the constraints of technology and that it's a process of trial and error, learning by doing.

Lessons learned

1. Introduce students to FabLab in small groups to make sure everyone sees and hears what is happening.

2. Introduce constraints of the technology and provide objects that can be touched to avoid disappointment.

\subsection{Background Research: Identifying Customers and Competitors}

In Session 4, we met at the university where researchers led students into thinking about why companies do background research. We tasked them to carry out 1) an online search of competitors, 2) observations of potential customers and 3) interviews of potential customers, in order to make sure there is a need for their business. Groups were to update their business plan based on the results. Students were restless despite teacher efforts to keep them in check. 
A teacher noted the change of scenery and instruction style might have this effect: In school they get stuff done, they're used to it. In a different environment, it is different. [...] It is a free environment, it affects them. As it is freer, there might have been more need for intervention. (Teacher 1)

The groups were slow to get started. Researchers and teachers circled around, trying to get the discussion going and answering questions. Several students voiced confusion about what it was they were supposed to be doing and if everyone should participate in all tasks. Search for competitors seemed to be easy, however interviews and observations were met with some resistance. The purpose of observations was hard to grasp and students had trouble coming up with interview questions. In addition, they did not like the idea of going up to a stranger asking to interview them. A teacher reflected that we perhaps allowed them too much freedom, and tasks could have been divided into smaller pieces for more structure: 15 minutes for example for interviews, and 30 mins for background research. Maybe a stronger structure and instruction. There was a bit too much freedom at the start (Teacher 2). In the end we could not keep track whether all groups accomplished their tasks but had to take their word for it. When recapping the results with the whole class, everyone listened intently, interested in hearing how others had done.

Lessons learned:

1. Do not expect students to take initiative and act independently during the early phases of the project.

2. Divide the tasks into smaller phases; Introduce them one at a time and give detailed instructions on how to carry them out. Help students assign roles and tasks to group members in complex tasks.

3. Build observations and interviews as a natural part of the working process, to lessen the awkwardness.

4. Inform students they need to present their results in the end, to make sure all groups carry them out.

\subsection{Acquiring Basic Skills in Design and Making}

Design and making activities started with learning to use design software at the school in Session 5. We prepared 3 tutorials for students: 1) Inkscape for vinyl cutter (sticker) 2) Inkscape for laser cutter (earrings/keychain) and 3) Tinkercad for 3D printer (keychain). Students were tasked to complete at least one tutorial and save the design. Instead of working in groups, they were free to experiment independently. As homework, they were to think about what they could design related to their business with the software.

It took some time for the students to get started and select a tutorial. Despite chatter, all seemed interested in the task. Even those first uninterested activated as the session progressed. Some had previous experience and were happy to show off their skills, completing the designs fast. One student considered making a keychain a highlight of the project: The most interesting part of the whole project was the designing with Tinkercad. We had possibility to make our own designed keychains and 3 D print them. (Boy 1)

Inkscape proved out to be more challenging, some voiced out their frustration and considered quitting. In the end, however, the stickers made with Inkscape proved to be a hit. Session 6, a second session for acquiring the basic skills, was held at the FabLab. After the students saw a couple of stickers come out and placed on laptops or phone covers, they started to create one design after another and soon the process was jammed. One reason was that of the four researchers and two teachers participating in the session, only two could effectively instruct the students with Inkscape. They were trying to make sure everyone had completed at least one tutorial as we wanted everyone to have the experience of succeeding and taking home an item they designed themselves. In addition, while students had been instructed to go and ask FabLab instructors to help them cut stickers out, some were shy or reluctant to ask them for help. When reflecting on digital fabrication, one student explains that while she liked the sticker, the process is very independent, and she did not have good ideas for future projects to do there: I really liked the end results. Like the stickers. I was impressed. About like, what you can do with this kind of technology. But I didn't understand very well how they were done. I don't have ideas [for what to do on my own in the future]. (Girl 2) In this phase, the teachers' role was mainly to make sure all groups were progressing and to tell the researchers if someone needed help. They agreed that when it comes to learning the basics, it was better that the researchers who had experience took charge, however they felt a little like outsiders during this session (and the subsequent making activities). Their feedback was that we could have incorporated their help in a more efficient way: With a well-set plan, teachers could work as facilitators, perhaps not the software, but the pedagogical side. Some things are learned along the way, knowing what works with the ninth graders. (Teacher 1) In general, this phase exemplified the challenges of managing the expectations and roles of different adults taking part in making projects with children and engaging the teachers in the making activities.

Lessons learned:

1. Involve teachers in the activities beforehand to engage them better when working with students.

2. Negotiate the roles and responsibilities of adult actors to take advantage of each other's strengths.

3. Get students familiar with FabLab instructors to facilitate their help effectively.

4. Ensure the positive experiences and sense of accomplishment for not to curb students' enthusiasm.

5. Present students simple projects to do on their own to lower the barrier of participation in the future.

\subsection{Designing and Making Something Related to the Business Idea}

Next, we guided the students back to group work. Sessions 7-9 were held at the FabLab, where researchers introduced students the importance of concept pictures, and scenarios in product design. Groups were tasked to create a concept picture to visualize how their product or service looks like, or a scenario to exemplify how it would be used. In addition, groups discussed the results of their homework: what they could design related to their business idea using the processes that they had learned earlier (2D design and vinyl or laser, cutter or 3D design and printing). Concept pictures and scenarios were produced with relatively little difficulty but coming up with something to make related to business ideas was difficult. 
This time we had anticipated free ideation might be challenging, and to help overcome blocks in creativity we arranged for each group to have an adult helping. In addition, we prepared a list of small projects for each group, in case they did not come up with one. The list was given to the dedicated adult and it worked as a conversation starter in some groups; some had difficulties though and were passive. One researcher, frustrated, wrote in her field notes: Even though instructions are clear, it is still surprisingly difficult to tell children what to do when they don't do anything on their own, not even when told to do something. It was still also unclear for some what was the point of the work altogether: One kid asks: "what use is this kind of imagining for?"

Once we made sure all groups had an idea, we let them work independently, designing and fabricating their items and updating their business plan and preparing for the final pitching. Learning from the previous sessions, we printed out our instructions, to help the students keep track of what needs to be done still, and who will be doing it. The role of researchers was to help in the design and making of the product, while teachers made sure groups were working on their business plan and pitch. In this phase in Sessions 8-9, students retreated to work on their own corners in the FabLab. At first, we were worried as it looked like there was not much communication going on: Many sat with their headphones on browsing their phone. When looking more closely and talking to them, we were happy to notice many were in fact doing something related to their group work - their way of working was just different than we anticipated. The facilitators able to help with more technical work were spread too thin in this phase, however, as all researchers did not have the needed skills. This frustrated the researchers, and most likely also the students, we assume.

There were also the unmotivated students. A teacher explained that as student work was not graded, it was harder to motivate them. He had expected them to be impressed by the possibilities of the space more: I had the presupposition that they would be happy and excited to be in a FabLab, but it wasn't the case. They said they don't want to do it as it doesn't affect their grade. (Teacher 1). Upon hearing this, we decided to make it known that the group that secures the most investments in the pitching wins movie tickets. This caused an immediate surge of energy. Groups were happy, competitive and chatty, and told us that we should have told this from the start. The teacher laughed: The tools of external motivation have been used. (Teacher 1)

Working methods varied a lot between groups. In some, the groups worked together on all tasks, in others, each participant had specific tasks. There were some that disengaged from the project and the work was not always evenly distributed. Tensions were also caused by the fact that individual designs were more interesting to some than group work. Reflecting back, a student reminisces a fight they had concerning this: He was doing his own thing. Sticker. He wasn't participating, he kinda thought he had finished our prototype and didn't need to do more. I got mad. [...] But at one point I was also doing my sticker when we were supposed to work on the project. I could have concentrated more too. (Girl 2)

Lessons learned:

1. Balancing individual learning with group activities is a challenging task that requires planning.
2. If possible, have a dedicated instructor for each group to assist in ideation and making activities.

3. Consider how to communicate the link between products clearly and services in use and all the 'imagining' done when developing a business idea further.

4. If there does not seem to be intrinsic motivation and external motivation is also missing (i.e., no grade), introducing competitive elements might spark action.

\subsection{Pitching the Business Ideas}

The project was wrapped up at the university in Session 10, where we arranged for four new researchers to act as investors in an event mimicking the TV-show Shark Tank. In the beginning of the session, we had breakfast together and gave groups time for final preparations. The atmosphere was excited. Groups had worked with teachers to practice pitches. They wrapped up their projects well and listened intently to others. Afterwards one reflected: The best part in my opinion was the last day when sharks invested money for our ideas. I liked to hear comments about our business plan and seeing what team wins. (Boy 2)

When presentations were over, the Sharks circled groups, asking questions and making investments. Each had 100000 Euros of "FabMoney" to divide between groups. They were given an instruction to give each group a portion as we wanted the excitement of the competition to last, and to avoid some groups getting a lot more than others. After the Sharks finished, we calculated which group received the biggest investment and announced the winner. We did not announce how much other groups received. In general groups were happy with how they wrapped up the project: Our idea and end result were not perfect, but I think we did a good job pitching (Girl 2). I learned that we need to have a better idea than competitors. I liked presentations and shark tank (Girl 1). Teachers were also happy with how the event wrapped up the project: Being in the business kitchen exposed them to entrepreneurship. Now they have concrete experience and idea what it is, how competitive it is. Shark Tank was really nice although they were nervous. (Teacher 1)

When reflecting on project goals, the teachers were impressed with end results, happy with what students accomplished and how students' teamwork skills improved. They saw the experience beneficial as students had to take more responsibility and initiative. In addition, as students learned the basics of entrepreneurship and ideating, the project fulfilled the expectations of the multidisciplinary learning entity. Students also reflected on group dynamics, discussing time restraints and realizing everyone needs to pull their weight in order to carry out a project like this. They voiced out that while it is hard, all ideas need to be heard: In the end we started to understand each other. In the beginning we were all over the place a bit. (Girl 2) I learned that coming up with a good idea takes a long time and everyone's voice needs to be heard. (Boy 2)

However, even after their positive experiences, in the end teachers had trouble envisioning how they could integrate making activities into normal teaching. One expressed she does not know what kind of projects she could do to tie them together with the subject matter: As an English teacher, it does not seem to be something to do regularly but there might be a place for it. It would be difficult to work with teachers from other subject [such as arts and crafts] (Teacher 2). 
The other teacher also brought up the need for careful planning, and limitations in technical skills: They need to cover lots of things and the planning to fit it into the teaching is time consuming. They need to be well structured, planned, and brief so that there would be some theory first. If it is about the digital fabrication it is better that the experts do it, and teacher supports. It would take so much time to learn to use the machines and the software (Teacher 1).

Lessons learned:

1. Less formal setting allows students to take more responsibility and initiative and build teamwork skills as the project progresses.

2. Preparing pitches tie together the making activities with the entrepreneurship aspect of the process.

3. Competitive pitch is a fun way to wrap up the project where students learn the importance of an idea.

4. To effectively integrate making into schoolwork, we need to envision ways that make it attractive to teachers and lower their barrier of entry.

\section{CONCLUDING DISCUSSION}

Inspired by the educational trends of digital fabrication and making as well as entrepreneurship education, we examined in this paper what are the challenges involved in combining digital fabrication with entrepreneurship education in the school context. So far, surprisingly little research has been conducted on the topic, even though the combination has the potential to empower children and increase their abilities to participate and shape the society and digitalization within, i.e., to act as protagonists [16] instead of passive consumers. Our study enables bringing in new, valuable aspects for the Protagonists role for children [16].

We contribute by presenting one example of how digital fabrication and making can be combined with entrepreneurship education with teenagers, aiming them to adopt the role of the Protagonist, driving digital business innovation. We have presented a number of challenges and lessons learned related to the different process phases that we believe are useful to the diverse group of practitioners coming together in Fab Labs and makerspaces to work with children, in order to identify and tackle potential pitfalls that may emerge. The overall takeaway message from the project is that it worked: the teachers were happy with the learning outcome - learning the combination of technical and entrepreneurship skills as well as soft skills of teamwork. We can still identify two overarching challenges that affected the working:

First, how to balance making activities with the entrepreneurship aspects of the project. The project started with business planning in groups, but after we introduced individual design tasks and gave students opportunities to fabricate their own keychains and stickers, it was hard to get the focus back on the group work and the businessrelated aspects. When we finally managed to do so, the end product seemed to be more important to groups than the business plan that was meant to be the backbone of the project. This might be because students felt the pressure of presenting something concrete in the final pitch. We focused a lot on getting positive first experiences with digital fabrication for all but learned that it is important to plan beforehand how to balance individual learning with project goals. Perhaps it would be better to introduce design and making as a separate entity first, and only after everyone has had a chance to experiment and learn the basic skills, move into applying them on a project where the focus is on innovation and entrepreneurship. However, in reality, arranging dedicated making activities during school hours can prove challenging because it would mean teachers having to give up time reserved for something else.

Another key challenge was negotiating the roles and responsibilities between the adult participants of the project (see also [23-25, 28]) researchers, teachers and FabLab instructors. Researchers strived to provide participating teachers all needed materials beforehand as well as inviting them to take part as much as they can. However, teachers rarely had time to go through the materials before the sessions. As the sessions unfolded, researchers emerged as the leaders and the role of the teachers was more to help manage groups and facilitate learning. On one hand, teachers voiced out that they would have enjoyed a bigger role but lacked the needed technical skills. On the other hand, they did not take an active role in planning any activities, even though they were offered possibilities for that. This caused us to start off the project different to what students were used to, which caused confusion among them. In a situation where all participating adults do not have technical skills, we suggest sharing the roles differently to how we did it. Teachers could lead daily activities by going through students' progress with the help of the business plan. Then, students could move into the specific daily activities instructed by researchers. Teachers could also lead the wrap up discussion for each day. As participating teachers pointed out, while we had the technical skills, they have more pedagogical know-how that is a huge resource when working with a group of teens that, as we learned, might be hard to motivate and keep in check. It is a key to try and find a balance. Thus, it is important to not consider only students as participants and but also engage teachers in the learning process. The teachers had, after all, envisioned having a bigger role in the project, but would not have time to acquire the skills needed to lead making activities. Instead of sending teachers materials and tutorials beforehand, perhaps more hands-on workshopping for them in the FabLab would have been a more engaging option and helped them to commit to planning as well as helped gain more skills to facilitate some technical parts. FabLab instructors were the third group of adults present in many sessions. However, students were shy to approach them to ask for help. Had we succeeded in including the FabLab facilitators better, it would have relieved some pressure from us during the design and making activities. Thus, we argue that in addition to helping students negotiate tasks and roles in their project group, same is needed when discussing the roles of multiple adult facilitators to avoid confusion.

From the Protagonist role perspective [18] we see a lot of value in the learning process of the project. In addition to learning about the basics of coming up with a business idea, a business plan and a pitch, all learned the basics of digital fabrication and prototyping. Students learned to take more initiative and responsibility and improved their team working skills. All these are part of the 21 st century skills $[39,40]$ and valuable from the Protagonist role: learning to understand different facets of technology development and use and learning that everybody can take a lead in developing technology and business. It was great to see in the end how students learned that all you need is a good idea, everyone's voice should be heard, 
and that you can create something to be proud of in a relatively short period.

To conclude, we think that this is valuable for the CCI/FabLearn researchers to consider: the skills children learn in CCI projects are increasingly everyday skills, compared to how they have previously belonged to the domain of adult experts. We argue it is important for researchers and practitioners alike to consider combining digital fabrication and making with ordinary, everyday topics that children encounter, to give children experiences and examples of how digital fabrication, design and making can be utilized in their future lives. We also align firmly with the entrepreneurial vision of the maker movement that sees making as an enabler of business innovation and key to entrepreneurship [22,38], while we also see the important value of the maker movement from the viewpoint of developing personal, meaningful objects for one's own use or for the good of the community. By combining the two, the children can get an initial understanding of the possibilities, which possibly sparks an interest for trying either or both out later.

As to the limitations of the study, we examine data from a project conducted with children in one country and city. As there is limited amount of literature available yet on the topic, this is an exploratory study, and more research is needed for finding best practices on how to combine entrepreneurship and innovation education with digital fabrication and making. Furthermore, the focus of the investigation was on lessons learned for practice. It would be interesting to examine more fundamentally which 21st Century Skills can be promoted in lessons with teenagers through the combination of these different approaches - entrepreneurship education, digital fabrication and making - and to what extent this combination is beneficial for the promotion of these skills or whether the approaches should be implemented separately.

\section{ACKNOWLEDGMENTS}

This project was funded by Finnish cultural foundation, North Ostrobothnia regional foundation.

\section{REFERENCES}

[1] Tilde Bekker, Saskia Bakker, Iris Douma, Janneke van der Poel, and Koen Scheltenaar. 2015. Teaching children digital literacy through design-based learning with digital toolkits in schools. International fournal of Child-Computer Interaction 5 , (September 2015), 29-38. DOI:https://doi.org/10.1016/j.ijcci.2015.12.001

[2] Paulo Blikstein. 2014. Digital Fabrication and 'Making' in Education. transcriptVerlag. Retrieved March 12, 2021 from https://www.degruyter.com/document/ doi/10.14361/transcript.9783839423820.203/html

[3] Russell E. Browder, Howard Aldrich, and Steven Walter Bradley. 2017. Entrepreneurship Research, Makers, and the Maker Movement. Proceedings 2017, 1 (August 2017), 14361. DOI:https://doi.org/10.5465/AMBPP.2017.14361abstract

[4] Russell E. Browder, Howard E. Aldrich, and Steven W. Bradley. 2019. The emergence of the maker movement: Implications for entrepreneurship research. four nal of Business Venturing 34, 3 (2019), 459-476.

[5] Annalisa Buffardi. 2021. Digital Making and Entrepreneurship. Imagine the Future. DOI:https://doi.org/10.1007/978-981-15-7383-5_13

[6] Sharon Lynn Chu, Rebecca Schlegel, Francis Quek, Andrew Christy, and Kaiyuan Chen. 2017. "I Make, Therefore I Am": The Effects of Curriculum-Aligned Making on Children's Self-Identity. In Proceedings of the 2017 CHI Conference on Human Factors in Computing Systems (CHI '17), Association for Computing Machinery, New York, NY, USA, 109-120. DOI:https://doi.org/10.1145/3025453.3025458

[7] Directorate-General for Education, Youth, Sport and Culture. 2019. Key competences for lifelong learning. Retrieved March 9, 2021 from 10.2766/569540

[8] Dale Dougherty. 2012. The Maker Movement. Innovations: Technology, Governance, Globalization 7, 3 (2012), 11-14

[9] Dalila Alves Durães. 2015. Gaming and Robotics to Transforming Learning. In Methodologies and Intelligent Systems for Technology Enhanced Learning, Springer
International Publishing, Cham, 51-56.

[10] Árni Már Einarsson and Morten Hertzum. 2020. How is learning scaffolded in library makerspaces? International fournal of Child-Computer Interaction 26, (December 2020), 100199. DOI:https://doi.org/10.1016/j.ijcci.2020.100199

[11] Peter Galvin, Nicholas Burton, and Richard Nyuur. 2020. Leveraging interindustry spillovers through DIY laboratories: Entrepreneurship and innovation in the global bicycle industry. Technological Forecasting and Social Change 160, (November 2020), 120235. DOI:https://doi.org/10.1016/j.techfore.2020.120235

[12] Guntram Geser, Eva-Maria Hollauf, Veronika Hornung-Prähauser, Sandra Schön, and Frank Vloet. 2019. Makerspaces as Social Innovation and Entrepreneurship Learning Environments: The DOIT Learning Program. Discourse and Communication for Sustainable Education 10, 2 (December 2019), 60-71. DOI:https: //doi.org/10.2478/dcse-2019-0018

[13] Anna-Lena Godhe, Patrik Lilja, and Neil Selwyn. 2019. Making sense of making: critical issues in the integration of maker education into schools. Technology, Pedagogy and Education 28, 3 (May 2019), 317-328. DOI:https://doi.org/10.1080/ 1475939X.2019.1610040

[14] Mark Hatch. 2013. The Maker Movement Manifesto: Rules for Innovation in the New World of Crafters, Hackers, and Tinkerers. McGraw-Hill. Retrieved March 15, 2021 from https://www.oreilly.com/library/view/the-maker-movement/ 9780071821124/

[15] Eva-Maria Hollauf, Veronika Hornung-Prähauser, Daria Podmetina, Elisabeth Unterfrauner, and Guntram Geser. 2020. Making social innovators - Novel innovation education for youth in makerspaces. Zenodo. DOI:https://doi.org/10.5281/ zenodo.4065521

[16] Netta Iivari and Marianne Kinnula. 2018. Empowering children through design and making: towards protagonist role adoption. In Proceedings of the 15th Participatory Design Conference: Full Papers - Volume 1 (PDC '18), Association for Computing Machinery, New York, NY, USA, 1-12. DOI:https://doi.org/10.1145/ 3210586.3210600

[17] Netta Iivari, Marianne Kinnula, Tonja Molin-Juustila, and Leena Kuure. 2017. Multiple voices in the maker movement - A nexus analytic literature review on children, education and making. In Proceedings of the 25th European Conference on Information Systems (ECIS), Guimarães, Portugal, 1919-1933. Retrieved from https://aisel.aisnet.org/ecis2017_rp/123

[18] Ole Sejer Iversen, Rachel Charlotte Smith, and Christian Dindler. 2017. Child as Protagonist: Expanding the Role of Children in Participatory Design. In Proceedings of the 2017 Conference on Interaction Design and Children (IDC '17), Association for Computing Machinery, New York, NY, USA, 27-37. DOI:https: //doi.org/10.1145/3078072.3079725

[19] Vegard Johansen. 8-11.7. Entrepreneurship education and entrepreneurial activity. In Proceedings of IntEnt 2007, Gdansk, University of Technology, Poland.

[20] Marilyn L Kourilsky and William B Walstad. 1998. Entrepreneurship and female youth: knowledge, attitudes, gender differences, and educational practices. Fournal of Business Venturing 13, 1 (January 1998), 77-88. DOI:https: //doi.org/10.1016/S0883-9026(97)00032-3

[21] Richard M. Lerner and William Damon. 2012. Entrepreneurship in Adolescence: A Relational Developmental Systems Approach. International fournal of Developmental Science 6, 3-4 (2012), 117-126. DOI:https://doi.org/10.3233/DEV-201212107

[22] Silvia Lindtner, Shaowen Bardzell, and Jeffrey Bardzell. 2016. Reconstituting the Utopian Vision of Making: HCI After Technosolutionism. In Proceedings of the 2016 CHI Conference on Human Factors in Computing Systems (CHI '16), Association for Computing Machinery, New York, NY, USA, 1390-1402. DOI:https: //doi.org/10.1145/2858036.2858506

[23] Iván Sánchez Milara, Kati Pitkänen, Jari Laru, Megumi Iwata, Marta Cortés Orduña, and Jukka Riekki. 2020. STEAM in Oulu: Scaffolding the development of a Community of Practice for local educators around STEAM and digital fabrication. International fournal of Child-Computer Interaction 26, (December 2020), 100197. DOI:https://doi.org/10.1016/j.ijcci.2020.100197

[24] Javier Monllor and Aracely Soto-Simeone. 2019. The impact that exposure to digital fabrication technology has on student entrepreneurial intentions. International fournal of Entrepreneurial Behavior \& Research 26, 7 (January 2019), 1505-1523. DOI:https://doi.org/10.1108/IJEBR-04-2019-0201

[25] Behnaz Norouzi, Marianne Kinnula, and Netta Iivari. 2019. Interaction Order and Historical Body Shaping Children's Making Projects-A Literature Review. Multimodal Technologies and Interaction 3, 4 (December 2019), 71. DOI:https: //doi.org/10.3390/mti3040071

[26] Arminda do Paço and Maria João Palinhas. 2011. Teaching entrepreneurship to children: a case study. Fournal of Vocational Education \& Training 63, 4 (December 2011), 593-608. DOI:https://doi.org/10.1080/13636820.2011.609317

[27] Maija Pienimäki, Marianne Kinnula, and Netta Iivari. 2021. Finding fun in nonformal technology education. IfCCI (2021). DOI:https://doi.org/100283

[28] Kati Pitkänen, Megumi Iwata, and Jari Laru. 2019. Supporting Fab Lab facilitators to develop pedagogical practices to improve learning in digital fabrication activities. In Proceedings of the FabLearn Europe 2019 Conference (FabLearn Europe '19), Association for Computing Machinery, New York, NY, USA, 1-9. DOI:https://doi.org/10.1145/3335055.3335061 
[29] Emilia Louisa Pucci and Ingrid Mulder. 2015. Star(t) to Shine: Unlocking Hidden Talents Through Sharing and Making. In Distributed, Ambient, and Pervasive Interactions (Lecture Notes in Computer Science), Springer International Publishing, Cham, 85-96. DOI:https://doi.org/10.1007/978-3-319-20804-6 8

[30] Thierry Rayna and Ludmila Striukova. 2021. Assessing the effect of 3D printing technologies on entrepreneurship: An exploratory study. Technological Forecasting and Social Change 164, (March 2021), 120483. DOI:https://doi.org/10.1016/j. techfore.2020.120483

[31] Rachel Charlotte Smith, Ole Sejer Iversen, and Mikkel Hjorth. 2015. Design thinking for digital fabrication in education. International fournal of Child-Computer Interaction 5, (September 2015), 20-28. DOI:https://doi.org/10.1016/j.ijcci.2015.10. 002

[32] Michael Stacey. 2014. The FAB LAB Network: A Global Platform for Digital Invention, Education and Entrepreneurship. Innovations: Technology, Governance, Globalization 9, 1-2 (2014), 221-238.

[33] FPFIS team. 2013. Learning and Skills for the Digital Era. EU Science Hub - European Commission. Retrieved May 4, 2021 from https://ec.europa.eu/jrc/en/ research-topic/learning-and-skills

[34] Gabriella Tisza, Sofia Papavlasopoulou, Dimitra Christidou, Netta Iivari, Marianne Kinnula, and Iro Voulgari. 2020. Patterns in informal and non-formal science learning activities for children-A Europe-wide survey study. International fournal of Child-Computer Interaction 25, (September 2020), 100184. DOI:https://doi.org/ 10.1016/j.ijcci.2020.100184

[35] Elisabeth Unterfrauner, Christian Voigt, and Margit Hofer. 2019. Participative evaluation with children in educational maker projects: Experiences from pilot action. In Proceedings of the 9th International Conference on Communities \&
Technologies - Transforming Communities (C\&T '19), Association for Computing Machinery, New York, NY, USA, 194-197. DOI:https://doi.org/10.1145/3328320. 3328372

[36] Elisabeth Unterfrauner, Christian Voigt, and Sandra Schön. 2019. Towards a Model of Early Entrepreneurial Education: Appreciation, Facilitation and Evaluation. In Methodologies and Intelligent Systems for Technology Enhanced Learning, 8th International Conference (Advances in Intelligent Systems and Computing), Springer International Publishing, Cham, 139-146. DOI:https://doi.org/10.1007/978-3-31998872-6_17

[37] Fanny Vainionpää, Netta Iivari, Marianne Kinnula, and Heidi Hartikainen. 2020. Aiming for Resemiotisation - Meanings Making and Co-Creation of Value Around an IT Course. ICIS 2020 Proceedings (December 2020). Retrieved from https: //aisel.aisnet.org/icis2020/digital_learning_env/digital_learning_env/4

[38] Leena Ventä-Olkkonen, Marianne Kinnula, Heidi Hartikainen, and Netta Iivari. 2020. Embedded assumptions in design and Making projects with children. In 32nd Australian Conference on Human-Computer Interaction (OzCHI '20), Association for Computing Machinery, New York, NY, USA, 178-188. DOI:https://doi.org/10. $1145 / 3441000.3441077$

[39] Karen E. Wilson, Shai Vyakarnam, Christine Volkmann, Steve Mariotti, and Daniel Rabuzzi. 2009. Educating the Next Wave of Entrepreneurs: Unlocking Entrepreneurial Capabilities to Meet the Global Challenges of the 21st Century. Social Science Research Network, Rochester, NY. DOI:https://doi.org/10.2139/ ssrn. 1396704

[40] World Economic Forum. New Vision for Education - Unlocking the Potential of Technology. Retrieved March 15, 2021 from http://widgets.weforum.org/nve2015/ 